\title{
From dichotomisation towards intersectionality in addressing covid-19
}

\author{
Anne-Sophie Jung and colleagues argue that understanding mechanisms of response to the \\ covid-19 pandemic as trade-offs reinforces false dichotomies and hamstrings attempts to create \\ stronger and more equitable health systems
}

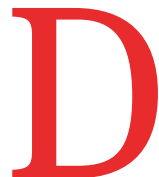

iscussions on covid-19 have produced dichotomised debates about priorities in pandemic response. These debates have played out in the media, in scientific briefings, and in academic discourse. Several papers have started to engage with the dichotomic framing of debates, including Escandòn and colleagues' reflection on how the transmission and infection of SARSCoV-2 are narrated. ${ }^{1}$ However, dichotomies exist beyond public health, and affect how covid-19 is understood, measured, and managed globally. Debate around the tradeoffs of various approaches is often counterproductive to strengthening pandemic responses. Political decisions steering the covid-19 response have greater and more nuanced consequences than dualisms can convey. Debates dichotomising national pandemic responses have been used as a tool to gain political advantage and divert attention from the underlying structural inequalities and power asymmetries driving the unfolding crises.

\section{KEY MESSAGES}

- Discussions on covid-19 have led to dichotomised debates about how to respond to the pandemic; this has created an understanding of the challenge as a zero-sum game (eg, "saving lives" or "saving livelihoods")

- Considering issues and interventions as trade-offs is false. Dichotomising debates has become a political tool that polarises opinions to gain political advantage

- We should understand challenges to health as highly nuanced and intersecting, and thus modify our approach to be guided by human rights principles and concerns about equity

- Moving away from artificial dichotomies will help reshape responses to the pandemic such that they are holistic and sustainable
Considering these complexities, we analysed the responses to covid-19 in 28 countries, and selected the seven highest and lowest performing countries measured as the number of deaths per capita directly related to covid-19 in November 2020. We also considered 14 countries in the middle performing category. Based on extensive review, a systematic comparative analysis, and consultations with experts on covid19 working in academia, government, and the private and not-for-profit sectors, we present six dichotomised debates. We describe how these dichotomies have been constructed and show how moving away from artificial dichotomies reshapes debates, such that they inform a more holistic and sustainable pandemic response. To unravel the complexity of these discussions, our analysis is guided by three questions (table 1) that bring to the fore six dichotomies:

- What is discursively prioritised during a pandemic?

- How is the response organised?

- How is health secured?

\section{What is prioritised during a pandemic?}

Social and economic interventions have been key parts of the global response to covid-19. With successive waves of infections, governments have ordered or extended lockdowns, despite concerns about economic consequences. Strong public health measures are often framed as prioritising public health over economic considerations.Conversely, postponing lockdown measures is framed as "saving the economy" or "saving livelihoods," which comes at the cost of public health or "saving lives."1-4 This is possibly the most discussed dichotomy, with authors agreeing that public health measures need to be supported by strong social welfare nets and balanced with economic and financial support. As governments start to view covid-19 as an endemic infectious hazard, this debate gains new traction. ${ }^{5}$ Policies to navigate this transition should secure the integration of public health measures, vaccinations, and socioeconomic support to shield populations, especially vulnerable ones, from the disparate and detrimental effects of covid-19.

Governments have prioritised certain scientific evidence. In response to an emerging pandemic, scientific advice informs the national approach, and discussion is dominated by an omnipresence of numbers, statistics, and graphs. The disciplinary composition of scientific committees opens up questions of legitimacy: who should be listened to, and which type of knowledge is seen as valuable during this health emergency? For countries analysed, the primacy of techno-bioscientific advice and the underrepresentation of social science expertise highlight what evidence is valued and deemed relevant to decision making.

Indeed, covid-19 taskforces often took a narrow view of science and did not consider social sciences or implementation based evidence in making recommendations. Often, the representation of civil society, community groups, and non-health experts was also left wanting (examples in box 1).

\section{How is the response organised?}

Discussions focus on whether governments should take a top-down or a bottom-up

\begin{tabular}{|c|c|c|c|}
\hline & Dichotomies & & \\
\hline \multirow{2}{*}{$\begin{array}{l}\text { What is prioritised during a } \\
\text { pandemic? }\end{array}$} & Public health & \multirow[t]{6}{*}{ Vs } & Economy \\
\hline & Technoscientific biomedical expertise & & Social science expertise \\
\hline \multirow{2}{*}{ How is the response organised? } & Public sector & & Private sector \\
\hline & Top-down & & Bottom-up \\
\hline \multirow{2}{*}{ How is health secured? } & Universal health coverage & & Global health security index \\
\hline & Human rights & & Public security \\
\hline
\end{tabular}


Box 1: Setting government recommendations: dos and don'ts from selected country examples

DO: Take advice from inclusive, interdisciplinary, and independent committees, making transparent who is advising the government

Independent and multidisciplinary advisory groups

- In Japan, the Novel Coronavirus Infectious Disease Control Subcommittee convened infectious disease specialists as well as local representatives, trade union executives, economists, and risk communication specialists, among others ${ }^{6}$

- In Mozambique, the Technical Scientific Commission was convened and included experts in public health, media, social science, and other sectors to inform the national response.

\section{Reporting structures}

- In Uruguay, the Honorary Scientific Advisory Group (GACH) held weekly meetings with subgroups, made biweekly reports to the Transition group, held special meetings with the president, and had daily contact with the government. Additionally, all announced measures had to be supported by scientists in GACH.

DON'T: Choose groups that are exclusively led by epidemiologists and biomedical experts with close ties to governments or executive leaders, and opaque reporting and group structures

\section{Excluding social and behavioural scientists and community experts}

- Scientific committees in the UK focused on epidemiological modelling but drew on behavioural sciences only narrowly, and missed the opportunity to consider human behaviour and daily routines

\section{Gaps in reporting structures}

- In Spain, the covid-19 Scientific and Technical Committee met during the first wave of the pandemic, but did not convene again.

approach in their response to the pandemic. Autocracy and democracy are compared as concepts for formulating effective responses. Evidence suggests that a strong response needs competent and empathetic leadership, clear command structures, local support, and strong community engagement. High performing countries used their network of community health workers (CHWs) to foster local leadership within communities. These CHWs took on a variety of roles and many were volunteers. They represent a powerful expression of solidarity, but must not be taken for granted by governments as a means to overcome gaps in public health and social welfare systems.

Many responses relied on collaboration with the private sector, forming publicprivate partnerships for testing and treatments, scaling up manufacturing of personal protective equipment, and leveraging quarantine facilities (box 2 offers examples). The challenges countries faced mirror the broader debates in publicprivate collaboration in mixed delivery health systems. National responses indicate the need to move away from the longstanding debates on the publicprivate divide and towards an integrated approach, with governments stewarding to leverage public and private sector capacity.
Index (GHSI) was the dominant measurement to identify which countries are well prepared to deal with biosecurity challenges, although it has been criticised for skewing in favour of high income countries. ${ }^{7}$ An alternative, Universal Health Coverage (UHC), has become the measurement of a health system's ability to deliver "health for all."

Yet, our analysis shows that many low performing countries have existing UHC schemes and score above 70 on the UHC index of service coverage. ${ }^{8}$ This same set of countries also scored within the top 50 of 195 countries in the 2019 GHSI. ${ }^{9}$ No clear pattern emerges when considering either the GHSI or UHC programmes as the determining indicator of country response. Even countries that score highly on GHSI and UHC have not necessarily been able to mitigate deaths from covid19 (UK, US). Questions are raised about the appropriateness of these indices for determining and ranking countries' capacities to respond to and mitigate health emergencies.

Tension between global health security and $\mathrm{UHC}^{10}$ is an expression of broader debates between public security and human rights in health. Public security seeks to ensure the protection of citizens and institutions against threats to wellbeing and to safeguard prosperity, but the ways in which this is achieved often contradict called upon to explain why a country has performed better or worse in its response to the pandemic. The Global Health Security
Box 2: Public-private collaborations during the pandemic: dos and don'ts from selected examples

DO: Enable surge capacity under institutional oversight through government stewardship in a transparent manner

Health service delivery

- Singapore mobilised its private primary care clinics under the Pandemic Preparedness Clinic scheme to provide triage support and treatment subsidised by the government.

Research and development

- South Korea strengthened relationships with private sector partners and biotechnology companies in the years between the outbreaks of Middle East respiratory syndrome and covid-19, resulting in timely public-private partnerships that delivered early diagnostic reagents for covid-19

DON'T: Outsource without oversight, accountability, and coordination

Health services

- In Peru, reports showed that private clinics charged for covid-19 testing, despite government guidelines advising otherwise.

Contact tracing

- The UK government outsourced certain public health functions, like contact tracing, to the private sector. These privatised efforts have been described as chaotic, and reports recount underqualified staff, limited effectiveness, and concerns about data protection.

Surge capacity

- Private hospitals in Sao Paolo started to share space, supplies, and expertise with underresourced public hospitals only when the latter had almost hit capacity 
the freedoms that human and social rights uphold. Border closures, national lockdowns, and increased surveillance ${ }^{1112}$ are examples of this dichotomy.

When a country secures its borders, it may be adjacent countries or those with strong trade ties that are most affected. Border closures to limit the spread of covid-19 disrupted global supply chains and affected trade partnerships, threatened food security, and contributed to shortages of medical and other essential supplies (box 3 gives examples). Securing public health by regulating the export of essential medical supplies represents a move towards protectionism, which stands in stark contrast with the notion of health as a universal human right. ${ }^{14}$ Migrant day labourers were hard hit by border closures and movement restrictions: some were stranded at borders, unable to return home, and others were unable to go to work as small scale trade across borders came to a halt. ${ }^{15}$ These challenges were exacerbated by domestic lockdowns, quarantines, movement restrictions (which were often implemented as blanket regulations), and which, across most countries reviewed, led to a sharp increase in economic hardship.

\section{Discussion}

\section{Shifting towards intersectionality}

When preparing a pandemic response, decision makers are required to consider, counter, or mitigate risks and inequalities, and these issues are often siloed and understood as trade-offs. Our analysis emphasises that debating trade-offs draws

Box 3: Public security measures: dos and don'ts from selected examples

DO: Focus health security on the right to health, grounded in human rights principles

Border closures with community engagement

- In New Zealand, citizens were kept well informed about border closures, lockdowns, and quarantines. Quarantine facilities and food delivery services were provided by the state. The government's emergency plan explicitly included assistance to Indigenous groups with access to healthcare and welfare services, although some inequalities persist.

Communication of risk and public health investment

- The government of Uruguay imposed no restrictive lockdowns, and trusted citizens to adhere to recommendations. It also prioritised building public health and laboratory capacity early in the pandemic to ensure adequate levels of testing and contact tracing.

DON'T: Disregard human rights

Scaling up measures in vulnerable groups only after outbreaks

- Singapore enacted robust measures to ensure the health and wellbeing of migrant workers only after a widespread outbreak of covid-19 in dormitories.

Politicising public health and social measures

- In the lead up to Uganda's presidential election in January 2021, the UN high commissioner for human rights accused authorities of enforcing covid-19 restrictions "more strictly to curtail opposition electoral campaign activities in a discriminatory fashion."13
We have discussed issues and data accumulated during the first year of the pandemic, but dichotomies persist and multiply as we move forward. Vaccine rollout, the dominant popular discourse suggests, sets an end to physical distancing and mask wearing, allowing everyone to return to "life as normal." Understanding that vaccination is only one of several public health measures remains particularly important while some populations have yet to receive vaccines. The increased focus on trade-offs has led to prioritisation of covid-19 above the crises it intersects with-whether in health or across domains. Strengthening preparedness and responses applies to every aspect of health, including antimicrobial resistance, HIV/ AIDS, malaria, or non-communicable diseases.

Similarly, ongoing failures to meaningfully centre climate action in global politics leaves us on track towards catastrophic global temperature rises, increasing vulnerabilities to the effects of environmental degradation, disasters, and infectious diseases. Additionally, before covid-19, post- and decolonial debates were trending in global health, but since covid less is being said around changing narratives. Indeed, continuing to coin covid-19 as an "unprecedented threat" only highlights a lack of understanding about the lived realities of health inequalitiesas well as environmental injusticesexperienced by marginalised, vulnerable, or racialised populations. ${ }^{21}$

\section{Conclusion}

This analysis brings to the fore the interconnectedness of issues that affect and determine health and wellbeing. Most importantly, responses to covid-19 are intrinsically political in the way debates are shaped, decisions are made, and priorities set. ${ }^{22}$ Our analysis shows that understanding issues and interventions as trade-offs is false. Instead, we must understand them as intersecting and thus create intersectional approaches to health challenges. To create better health interventions decisions must be guided by concerns about equity and human rights, but this requires sustained efforts, long term planning, and investment from governments. We must also apply lessons learnt to improve and rebuild health and wellbeing at the intersection of climate justice, international development, security, and gender equality.

We acknowledge support from the Independent Panel for Pandemic and Preparedness \& Response Secretariat. 
Contributors and sources: A-SI, VH, and HL-Q conceived and designed the analysis paper. A-S, VH, RN, SMA, and HL-Q collected the data. A-SJ, $\mathrm{VH}, \mathrm{RN}$, and $\mathrm{HL}-\mathrm{Q}$ analysed the data and drafted the manuscript with input from all authors. All authors contributed to revising the manuscript. This analysis was part of the work commissioned by the Independent Panel for Pandemic Preparedness \& Response, which reviewed the national responses of 28 countries. Data used for the analysis were collected through three complementary methods: (1) literature review of peer-reviewed papers, policy documents, public reports, and articles that examined national and sub-national policy responses; (2) semi-structured interviews with country experts and national government written submission of selected countries about their own account of the measures implemented to contain covid-19; (3) validation of country specific data by experts through written consultation and round table discussion.

Patient involvement: No patients were involved in this analysis.

Competing interests: We have read and understood the BMJ policy on declaration of interests and have the following interests to declare: All authors declare no conflict of interest. The Secretariat of the Independent Panel for Pandemic Preparedness and Response is independent.

Provenance and peer review: Commissioned, externally peer reviewed.

This collection of articles was proposed by The Independent Panel for Pandemic Preparedness and Response; open access fees were funded by WHO and Singapore's National Medical Research Council (NMRC) CG/C026/2017_NUHS). The BMJ commissioned, peer reviewed, edited, and made the decision to publish these articles. Kamran Abbasi was the lead editor for The BMJ.

Anne-Sophie Jung, research fellow ${ }^{1}$

Victoria Haldane, researcher ${ }^{2}$

Rachel Neill, researcher ${ }^{3}$

Melisa Mei Jin Tan, researcher ${ }^{4}$

Salma M Abdalla, secretariat member, research fellow 5,6

Michael Bartos, secretariat member ${ }^{5}$

Pami Shresha, researcher ${ }^{4}$

Alvin Qijia Chua, researcher ${ }^{4}$

Anders Nordström, head of the secretariat ${ }^{5}$

Helena Legido-Quigley, associate professor ${ }^{1,4,5}$

${ }^{1}$ London School of Hygiene and Tropical Medicine, UK

${ }^{2}$ Institute of Health Policy, Management and

Evaluation, University of Toronto, Canada

${ }^{3}$ Johns Hopkins Bloomberg School of Public Health, USA
${ }^{4}$ Saw Swee Hock School of Public Health, Singapore ${ }^{5}$ The Independent Panel for Pandemic Preparedness and Response Secretariat

${ }^{6}$ School of Public Health, Boston University, USA Correspondence to: A-S Jung Anne-Sophie.Jung@Ishtm. ac.uk

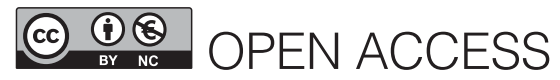

This is an Open Access article distributed under the terms of the Creative Commons Attribution IGO License (https://creativecommons.org/licenses/ by-nc/3.0/igo/), which permits use, distribution, and reproduction for non-commercial purposes in any medium, provided the original work is properly cited.

\section{Check for updates}

1 Escandón K, Rasmussen AL, Bogoch II, et al. COVID-19 false dichotomies and a comprehensive review of the evidence regarding public health, COVID-19 symptomatology, SARS-CoV-2 transmission, mask wearing, and reinfection. BMC Infect Dis 2021:21:710. doi:10.1186/s12879-021-06357-4

2 Smithson M. Data from 45 countries show containing COVID vs saving the economy is a false dichotomy. The Conversation. 2020. https://theconversation. com/data-from-45-countries-show-containing-covidvs-saving-the-economy-is-a-false-dichotomy-150533

3 Ferreri E. Prioritizing economy over public health the wrong approach, scholars say. Duke Today Campus, Medicine. 2020. https://today.duke.edu/2020/08/ prioritizing-economy-over-public-health-wrongapproach-scholars-say

4 Prasad V, Sri BS, Gaitonde R. Bridging a false dichotomy in the COVID-19 response: a public health approach to the 'lockdown' debate. BMJ Glob Health 2020:5:2909. doi:10.1136/bmigh-2020-002909

5 De Foo C, Grépin KA, Cook AR, et al. Navigating from SARS-CoV-2 elimination to endemicity in Australia, Hong Kong, New Zealand, and Singapore. Lancet 2021;398:1547-51. doi:10.1016/S01406736(21)02186-3

6 Sugiyama S. New Japan coronavirus subcommittee aims for fresh start at first meeting. The Japan Times 6 July 2020.

7 Razavi A, Erondu N, Okereke E. The Global Health Security Index: what value does it add?BMJ Glob Health 2020;5:e02477. doi:10.1136/ bmigh-2020-002477

8 Global Health Observatory. By category Index of service coverage-data by country. World Health Organization, 2020

9 Global Health Security Index. 2019. https://www. ghsindex.org/

10 Wenham C, Katz R, Birungi C, et al. Global health security and universal health coverage: from a marriage of convenience to a strategic, effective partnership. BMJ Glob Health 2019;4:e001145. doi:10.1136/bmjgh-2018-001145

11 Sekalala S, Dagron S, Forman L, Meier BM. Analyzing the human rights impact of increased digital public health surveillance during the COVID-19 Crisis. Health Hum Rights 2020;22:7-20.

12 Davis SLM, Williams C. Enter the cyborgs: health and human rights in the digital age. Health Hum Rights 2020;22:1-6

13 UN High Commissioner for Human Rights. Press briefing notes on Uganda [internet]. Spokesperson for the UN High Commissioner for Human Rights: Ravina Shamdasani. 2021 https://www. ohchr.org/SP/NewsEvents/Pages/DisplayNews. aspx?News $\mid \mathrm{D}=26645$ \&Lang $\mid \mathrm{D}=\mathrm{E}$

14 Mercy Corps. A clash of contagions: The impact of COVID-19 on conflict in Nigeria, Colombia and Afghanistan. 2021. mercycorps.org/researchresources/clash-of-contagions-impact-covid-19conflict

15 Reliefweb. Rising up to the challenge: COVID-19 guidelines amidst border closures and a pandemicworld. 2021. https://reliefweb.int/report/world/ rising-challenge-covid-19-guidelines-amidstborderclosures-and-pandemic

16 Cho S, Crenshaw KW, McCall L. Toward a field of intersectionality studies: theory, applications, and praxis. Signs / Women Cult Soc 2013;38:785-810. doi:10.1086/669608.

17 Birchall J. Resource guide: Covid-19, gender and intersectionality. Institute of Development Studies. 2021. https://opendocs.ids.ac.uk/opendocs/ bitstream/handle/20.500.12413/16745/ Covid19\%20Gender\%20and\%20 Intersectionality\%20Resource\%20Guide. pdf? sequence $=3$.

18 Leach M, MacGregor H, Scoones I, Wilkinson A. Post-pandemic transformations: How and why COVID-19 requires us to rethink development. World Dev 2021:138:105233. doi:10.1016/i. worlddev.2020.105233

19 Hurd ES. Beyond religious freedom: the new global politics of religion. Princeton University Press, 2017.

20 Ntumba HCK, Bompangue D, Situakibanza H, Tamfum JM, Ozer P. Ebola response and community engagement: how to build a bridge? Lancet 2019;394:2242. doi:10.1016/S01406736(19)32532-2

21 Büyüm AM, Kenney C, Koris A, Mkumba L, Raveendran Y. Decolonising global health: if not now, when?BMJ Glob Health 2020;5:e003394. doi:10.1136/bmjgh-2020-003394

22 Davies SE, Wenham C. Why the COVID-19 response needs International Relations. Int Aff 2020;96:122751. doi:10.1093/ia/iiaa135

Cite this as: $B M J$ 2021;375:e067500 http://dx.doi.org/10.1136/bmj-2021-067500 